\title{
Simultaneous acid exposure and erosive particle wear of thermoset coatings
}

\author{
Møller, Victor Buhl; Dam-Johansen, Kim; Frankær, Sarah Maria; Kiil, Søren
}

Published in:

Journal of Coatings Technology and Research

Link to article, DOI:

10.1007/s11998-018-0058-3

Publication date:

2018

Document Version

Peer reviewed version

Link back to DTU Orbit

Citation (APA):

Møller, V. B., Dam-Johansen, K., Frankær, S. M., \& Kiil, S. (2018). Simultaneous acid exposure and erosive particle wear of thermoset coatings. Journal of Coatings Technology and Research, 15(3), 457-469. https://doi.org/10.1007/s11998-018-0058-3

\section{General rights}

Copyright and moral rights for the publications made accessible in the public portal are retained by the authors and/or other copyright owners and it is a condition of accessing publications that users recognise and abide by the legal requirements associated with these rights.

- Users may download and print one copy of any publication from the public portal for the purpose of private study or research.

- You may not further distribute the material or use it for any profit-making activity or commercial gain

- You may freely distribute the URL identifying the publication in the public portal 


\title{
Simultaneous acid exposure and erosive particle wear of thermoset coatings
}

\author{
Victor Buhl Møller ${ }^{a *}$, Kim Dam-Johansen ${ }^{a \dagger}$, Sarah Maria Frankær ${ }^{b \ddagger}$ Søren Kiil ${ }^{a \S}$ \\ ${ }^{a}$ CoaST, Department of Chemical and Biochemical Engineering \\ Technical University of Denmark, DTU \\ Building 229, DK-2800 Kgs. Lyngby, Denmark \\ ${ }^{b}$ Hempel A/S, Lundtoftegårdsvej 91, DK-2800 Kgs. Lyngby, Denmark
}

\begin{abstract}
Handling acidic chemicals is a challenge in the chemical industry, requiring a careful choice of contact material. Certain thermoset organic coatings are applicable in low pH environments, but when particulate erosion is also present the performance demand is increased. This is the case in e.g. stirred tanks for agitated leaching of copper ore, where sulfuric acid is mixed with an erosive slurry.

A pilot-scale agitated leaching tank was designed and constructed to explore the performance of selected thermoset coatings in such an environment. For reference, simple immersion experiments were conducted. Coating durability was estimated by observing the film thickness change during exposure. It was found to be a function of film swelling and film contraction, due to chemical exposure, as well as the "polishing" caused by erosive wear. Film reduction rates varied with radial position in the tank bottom-placed coating samples. Maximum rates were found about halfway between reactor center and wall. Polishing rates also varied significantly with acid concentration, most likely due to chemical reactions taking place between the acid and the coatings, damaging surface mechanical properties, similar to the erosion/corrosion type phenomena found in metals.
\end{abstract}

\footnotetext{
*Tel.: +45-4525-2923 E-mail address: vibum@kt.dtu.dk

${ }^{\dagger}$ Tel.: +45-4525-2845 E-mail address: kdj@kt.dtu.dk

¥Tel.: +45-4527-3633 E-mail address: samfr@hempel.com

${ }^{\S}$ Corresponding author. Tel.: +45-4525-2827 E-mail address: sk@kt.dtu.dk
} 
A vinyl ester-based coating was the most resistant to the simultaneous erosive/acidic exposure, with a maximum polishing rate of $3.24 \pm 0.61 \mu \mathrm{m} /$ week, while novolac epoxy and polyurethane coatings showed high polishing rates of $11.7 \pm 1.50$ and $13.4 \pm 0.57 \mu \mathrm{m} /$ week, respectively.

Keywords: Acid leaching, Agitated leaching, Dry film thickness, Coating analysis, Erosion, Barrier coating.

\section{Introduction}

Whenever acidic chemicals are encountered in the chemical industry, a careful choice has to be made regarding the material selection for pipes, tanks, immersed equipment and secondary exposure areas. One option is to select acid resistant ceramics, metal alloys or reinforced plastics as bulk materials for construction. Another is to utilize a cheap bulk material and enhance the chemical resistance of its surface by applying a 0.8 to $3.8 \mathrm{~mm}$ thick layer of an organic thermoset coating. Kelley [1] estimated costs of material and installation of fiberglass-reinforced plastic (FRP) constructions in 2010 , to $1000 \$ / \mathrm{m}^{2}$, compared to $3000 \$ / \mathrm{m}^{2}$ for an alloy material with similar acid resistance. A comprehensive study of acid resistant inorganic and organic materials can be found in a recent review paper [2].

There are many industries where acid-resistant organic materials have potential as protective coatings. Examples include chemical transport in rail-car tanks, wet desulfurization plants and sour sewage treatment [2]. Also metal refining processes utilize acids, specifically agitated leaching of copper ore, where diluted sulfuric acid is used to dissolve copper-rich minerals [3. Fig. 1 . shows a series of agitated leaching tanks.

The present work describes experiments with coating samples in a pilot-scale agitated leaching tank and supporting immersion experiments. The purpose was to assess coating durability and 
estimate lifetimes under full-scale agitated leaching tank conditions, and to investigate coating degradation mechanisms.

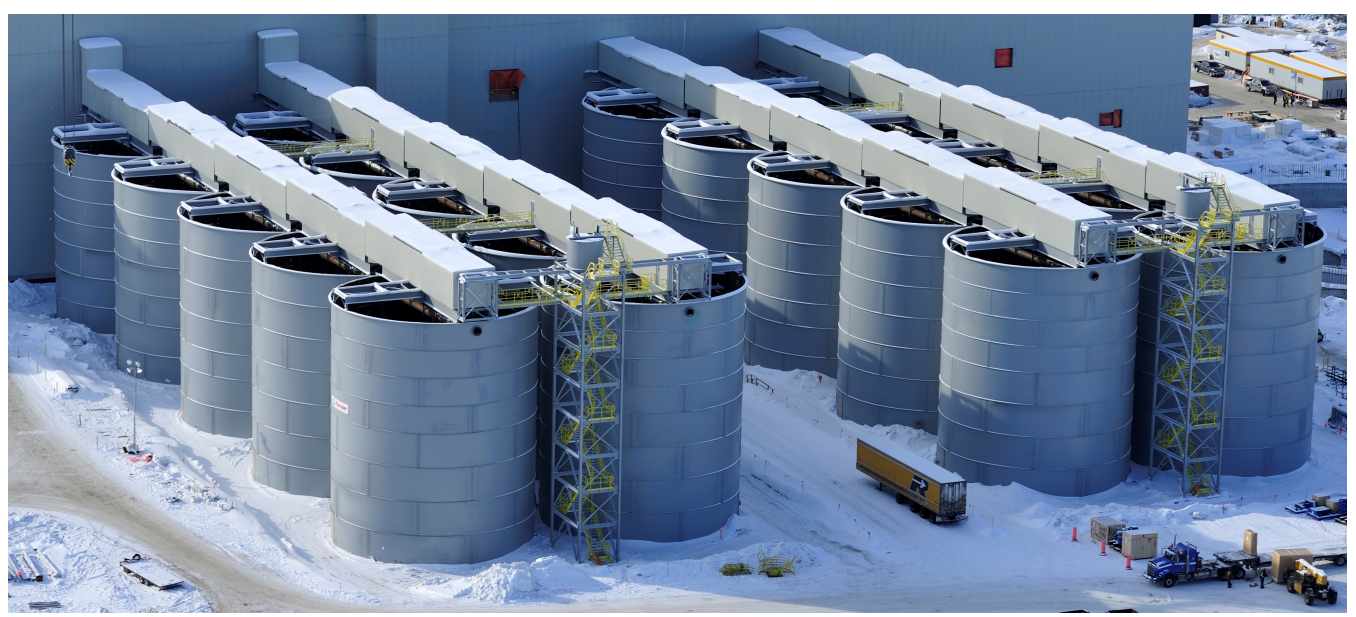

Figure 1: A series of industrial-scale agitated leaching tanks, used in industrial processing of mineral ore, located in Cochrane, Ontario, Canada. Notice the truck in the bottom right hand corner for scale. Courtesy and copyright Fournier Indsutries.

\section{Agitated leaching}

Agitated leaching of copper-rich minerals is a process in the extraction and refining of pure copper. The purpose is to dissolve the copper-rich minerals from an up-concentrated mineral broth, which can later be purified by electrowinning [3. This is done by adding sulfuric acid to the mineral slurry, while heating and stirring the mixture in leaching tanks [4]. Agitated leaching conditions consist of high temperatures $\left(75\right.$ to $\left.80{ }^{\circ} \mathrm{C}\right)$, acidity $(\mathrm{pH} \approx 1.0)$, and erosive particles. This combination of acids and erosion makes leaching tanks a special case for coating application, because products have to be resistant to both factors simultaneously. The present lack of knowledge regarding the degradation mechanisms of organic thermoset coatings under such conditions, prevents accurate predictions of coating performance, and is a hindrance to its use in practice. 


\section{Degradation mechanisms}

The environment in an agitated leaching reactor can cause coating failure via multiple pathways:

- Chemical degradation through irreversible chemical reactions between the coating and exposure chemical(s).

- Mechanical degradation by wear of the coating surface from the continuous impact of suspended solids.

- Physical degradation by reversible diffusion of chemicals into and through the coating film.

Detailed explanations and studies into physical and chemical degradation of organic coatings are covered in [2].

The mechanical degradation in leaching reactors can be described as erosion, freely moving particles impinging the coating surface, chipping away material. It should not be confused with sliding, abrasive wear, such as that performed by the taber abraser [5]. The erosive intensity in a leaching tank depends on the nature of the erodant, the coating material and the environment. Factors such as particle size, density, shape, speed, impact angle, hardness relative to the coating, and impact frequency are important. The liquid density can also influence erosion intensity as it can cushion particle impacts [6, 7]. While the effects of the chemical environment is not an area of much study, it has been suggested to play a role in determining erosion intensity [8].

Erosive wear should preferably be investigated in an environment similar to its actual use, to obtain comparative data on coating durability. No studies on the effects of simultaneous chemical and erosive exposure on organic coatings, have been found. This dual exposure is established in the pilot-scale leaching reactor used for the current study. 


\section{Replicating leaching conditions}

To simulate full-scale operations, a pilot plant has to mimic the erosive and chemical exposure conditions. The following is a description of the pilot-scale reactor set-up in comparison with a full-scale tank reactor.

\section{Downscaling of an industrial leaching reactor}

A leaching tank of the type considered in this work consist of a contiously stirred reactor with two different impeller types on the vertical axis. The pilot-scale set-up is designed to mimic the conditions inside an industrial agitated leaching reactor and allow the user to remove and insert coating samples for continuous analysis. The relative dimensions of the tank, impeller and baffles are the same as in a full-scale agitated leaching reactor. Fig. 2 shows some of these dimensions relative to the impeller diameter, which are both $130 \mathrm{~mm}$ for the pilot-scale reactor. 


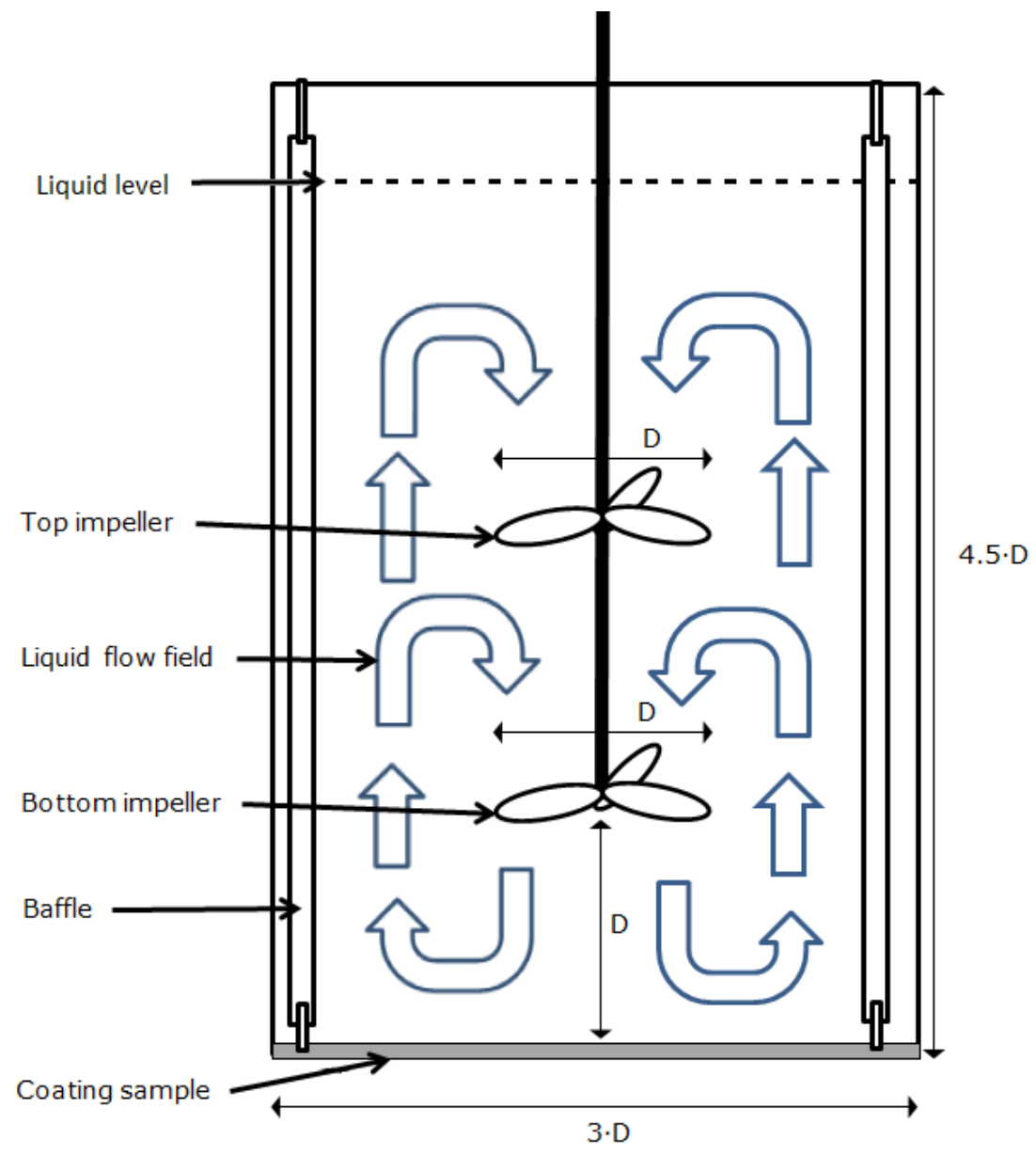

Figure 2: Cross-sectional diagram of the pilot-scale leaching reactor. The liquid flow fields are caused by the axial pumping impellers, as described in reference [9]. Relative dimensions are given with respect to the impeller diameter $D=130 \mathrm{~mm}$. The reactor is filled to $90 \%$ capacity.

The impeller types chosen replicate those found in industrial reactors, optimized for suspending particles by pumping the slurry axially towards the reactor bottom. The liquid flow fields are shown also in Fig. 2. Radial flow is also present, but vortexing is avoided by the presence of baffles. Typically, the stirring intensity used lies around 1 to $5 \mathrm{~kW} / \mathrm{m}^{3}$ [10], which is above the minimum requirement for full particle suspension, based on the Zwietering correlation [11]. A stirring intensity of $3.7 \mathrm{~kW} / \mathrm{m}^{3}$ was chosen for this study, corresponding to a mixing speed of 1000 RPM in the 68 l pilot-reactor. This provides a tank Re number greater than 1000, thereby 
creating turbulent flow in the pilot reactor, same as full-scale leaching reactors [12]. Table 1 shows a comparison in mixing conditions for a full-scale tank and the pilot-scale reactor. Typical full-scale leaching tanks can have diameters from 3 to $10 \mathrm{~m}$ (liquid volume of 28.6 to $1060.3 \mathrm{~m}^{3}$ ), while the pilot-scale diameter is $0.4 \mathrm{~m}$.

Table 1: Comparison of mixing conditions in a pilot-scale reactor with a tank diameter of $0.4 \mathrm{~m}$ and a small full-scale reactor with a tank diameter of $3 \mathrm{~m}$, both with a stirring intensity of 3.7 $\mathrm{kW} / \mathrm{m}^{3}$.

\begin{tabular}{|c|c|c|c|c|c|}
\hline $\begin{array}{l}\text { Scale } \\
\text { (volume) }\end{array}$ & $\begin{array}{l}\text { Impeller } \\
\text { diameter } \\
{[\mathrm{m}]}\end{array}$ & $\begin{array}{l}\text { Impeller tip } \\
\text { speed }[\mathrm{m} / \mathrm{s}]\end{array}$ & Re of $\operatorname{tank}^{a}$ & $\begin{array}{l}\text { Suspension, } \\
\mathrm{RPM}\left[\mathrm{min}^{-1}\right]^{a}\end{array}$ & $\begin{array}{l}\mathrm{RPM} \quad\left[\mathrm{min}^{-1}\right] \\
\text { at } 3.7 \mathrm{~kW} / \mathrm{m}^{3 a}\end{array}$ \\
\hline $\begin{array}{l}\text { Pilot-scale } \\
(68 \mathrm{l})\end{array}$ & 0.13 & 6.8 & $8.4 \cdot 10^{5}$ & 360 & 1000 \\
\hline $\begin{array}{l}\text { Full-scale } \\
(28600 \mathrm{l})\end{array}$ & 1.05 & 12.7 & $1.3 \cdot 10^{7}$ & 60 & 230 \\
\hline
\end{tabular}

${ }^{a}$ The power contribution of each impeller used to derive these values, are calculated separately using equations for single impeller systems [11, 12].

Erosive and chemical environment

Solid feeds to agitated leaching reactors consist of an up-concentrated mixture of calcopyrite $\left(\mathrm{CuFeS}_{2}\right)$, zinc and iron sulfides and oxides, and insoluble quartz. This copper concentrate was also used in the pilot-scale experiments, ensuring the same particle size, shape, density and hardness to imitate the erosive conditions. The particle load for industrial processes can vary depending on the copper content, but is often between 7 to 16 wt. \% [13]. 
In practice, agitated leaching reactors are placed in series, with each reactor operating at steady state conditions with continuous feeding of slurry and removal of product. Achieving this in lab scale is not feasible, and experiments were instead run using a single batch of solids. This causes a continuous fluctuation in chemical concentrations and particle size distribution. To maintain near constant conditions in the pilot-scale reactor, $\mathrm{pH}$ was adjusted using either concentrated sulfuric acid or sodium hydroxide pellets.

Due to reactivity of the particles with the surrounding medium, erosive conditions change somewhat throughout the course of reactor experiments. Two small-scale experiments were carried out to investigate the weight loss of particles as time progresses. In both experiments, $20 \mathrm{wt}$. $\%$ particles were immersed in $0.15 \mathrm{M} \mathrm{H}_{2} \mathrm{SO}_{4}$ under stirring. One experiment was performed at ambient temperature while the other was heated to $45 \pm 3{ }^{\circ} \mathrm{C}$. The particle weight loss was measured by filtering the slurry and drying the particle filter cake at $70{ }^{\circ} \mathrm{C}$ for $24 \mathrm{~h}$ before taking a weight measurement. Fig. 3 depicts the weight loss rates. It was found that the weight loss of particles plateaued after around $13 \mathrm{~h}$ of exposure, and that heating accelerated this procedure, but did not change the plateau. 


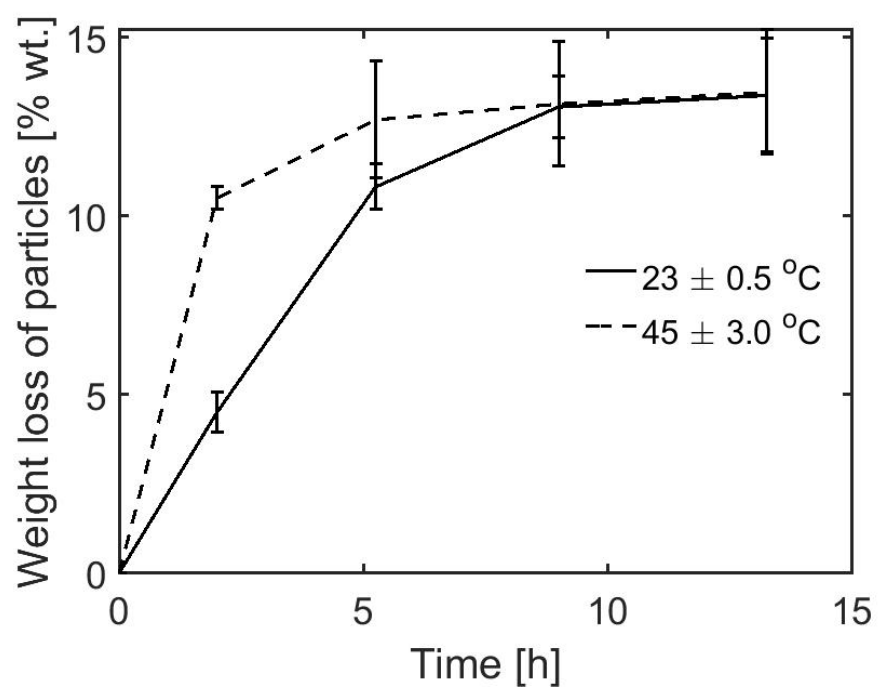

Figure 3: Transient weight loss of erosive particles in $0.15 \mathrm{M} \mathrm{H}_{2} \mathrm{SO}_{4}$.

Particle shapes were monitored throughout the course of reactor experiments, with no significant changes observed. Particle size distributions were also monitored throughout reactor experiments. The largest particles are about $100 \mu \mathrm{m}$. The mean volume spherical diameter oscillates between 17 and $30 \mu \mathrm{m}$.

The particle weight loss plateaus, the $\mathrm{pH}$ can be adjusted throughout an experiment, and the PSD and particle shape are relatively stable. For these reasons the conditions inside the pilot-scale leaching reactor, running in batch mode, are stable enough to simulate steady state conditions as would be found in continuous mode.

\section{Experimental}

Two experimental series were performed using the pilot-scale leaching tank. One with harsh conditions mimicking those found in real-life scenarios and one with milder conditions with elevated pH. Separate immersion experiments were also performed with coated samples in chemical jars 
inserted in a temperature regulated oven. Those experiments were done to show DFT changes caused by chemical diffusion and reaction, without the presence of erosion. An overview of the experimental conditions are shown in Table 2, The "Harsh" conditions for the reactor and immersion experiments were made as similar as possible, the same is true for the "Mild" condition experiments.

Table 2: Overview of experimental conditions. All experiments were performed at $75{ }^{\circ} \mathrm{C}$. "Harsh" conditions imitate the chemical environment in a real life leaching reactor. "Mild" conditions refer to experiments without the stress of low $\mathrm{pH}$ exposure.

\begin{tabular}{|c|c|c|c|c|}
\hline Experiment & \multicolumn{2}{|c|}{ Pilot-scale reactor } & \multicolumn{2}{|c|}{ Immersion in jars } \\
\hline Condition & Harsh & Mild & Harsh & Mild \\
\hline $\begin{array}{l}\mathrm{H}_{2} \mathrm{SO}_{4} \text { concentration } \\
{[\mathrm{mol} / \mathrm{l}]}\end{array}$ & $0.1 \pm 0.038$ & $5 \cdot 10^{-3} \pm 4.9 \cdot 10^{-3}$ & $0.106 \pm 10^{-3}$ & $10^{-4}$ \\
\hline $\mathrm{pH}$ & $1.03 \pm 0.17$ & $3.5 \pm 1.5$ & $0.975 \pm 0.005$ & 3.9 \\
\hline $\begin{array}{l}\mathrm{Cu}(\mathrm{II}) \text { concentration } \\
{[\mathrm{g} / \mathrm{l}]}\end{array}$ & $8.4 \pm 6.3$ & $0.88 \pm 0.88$ & 4.68 & 0 \\
\hline Particle load [wt. \%] & $18 \pm 2$ & $18 \pm 2$ & 0 & 0 \\
\hline $\begin{array}{l}\text { Stirring intensity } \\
{\left[\mathrm{kW} / \mathrm{m}^{3}\right](\mathrm{RPM})}\end{array}$ & $3.7(1000)$ & $3.7(1000)$ & None & None \\
\hline
\end{tabular}

\section{Coatings and curing}

Five different coatings were utilized, all of which are composed of resins recommended in the chemical industry for acid exposure purposes [14]. The coating types include a vinyl ester, a 
polyurethane, two amine-cured and one amide-cured novolac epoxies. Composition details are provided in Table 3. Substrates were made of 316 L SS and coatings were spray-applied and post-cured at $60{ }^{\circ} \mathrm{C}$ for two days. Samples for the pilot-scale reactor were quarter circles with a side length of $200 \mathrm{~mm}$ and thickness of $4 \mathrm{~mm}$. Samples for immersion experiments were $100 \mathrm{x}$ $50 \times 4 \mathrm{~mm}$. Fig. 7 shows the reactor and immersion samples.

Table 3: Main components of coatings used in the investigation. Only the PU coating contained solvent. $\mathrm{Eq}_{\text {Curing }} / \mathrm{Eq}_{\text {Resin }}$ is the ratio of curing agent to binder equivalents, defining the relative mixture stoichiometry of functional groups. Amine A and B contain different ratios of aliphatic and cycloaliphatic amines.

\begin{tabular}{|c|c|c|c|c|c|}
\hline Coating (code) & Resin & Curing agent & $\begin{array}{l}\text { EqCuring/ } \\
\text { EqResin }_{\text {Re }}\end{array}$ & Fillers/pigments & $\begin{array}{l}\text { Dry film } \\
\text { thickness } \\
{[\mu \mathrm{m}]}\end{array}$ \\
\hline Vinyl ester (VE) & Vinyl ester & Peroxide & NA & $\begin{array}{l}\text { Glass-flake and titanium } \\
\text { dioxide }\end{array}$ & $650 \pm 30$ \\
\hline $\begin{array}{l}\text { Novolac epoxy } 100 \% \text { solids } \\
\text { (NE1) }\end{array}$ & Bisphenol F epoxy & Amine A & 0.9 & $\begin{array}{l}\text { Quartz, baryte and ti- } \\
\text { tanium dioxide }\end{array}$ & $550 \pm 20$ \\
\hline Novolac epoxy (NE2) & Bisphenol F epoxy & Amine B & 1.0 & $\begin{array}{l}\text { Talc, feldspar and ti- } \\
\text { tanium dioxide }\end{array}$ & $610 \pm 60$ \\
\hline Novolac epoxy (NE3) & Bisphenol F epoxy & Amide & 0.8 & $\begin{array}{l}\text { Quartz, baryte and ti- } \\
\text { tanium dioxide }\end{array}$ & $870 \pm 170$ \\
\hline Polyurethane (PU) & Styrene acrylate & Isocyanate & 1.1 & $\begin{array}{l}\text { Baryte, calcium carbon- } \\
\text { ate and titanium dioxide }\end{array}$ & $590 \pm 30$ \\
\hline
\end{tabular}




\section{Procedure}

\section{Reactor experiments}

The completed pilot-scale agitated leaching reactor set-up is shown in Fig. 4 with the reactor lid raised, a close up of the impellers is given in Fig. 5. The reactor can move on rails to allow better access for removing and inserting coating samples. To initiate experiments, the reactor was set in the open position and coating samples were inserted in the bottom of the stirred reactor as shown in Fig. 6. The tank was then closed and filled with selected chemicals and particles and heated. To safely remove coating samples, the acid slurry was emptied into the storage tank, and the reactor was washed with tap water. Samples were removed every seven days and dried with paper towels for visual inspection and DFT analysis, thereafter re-inserted in the reactor. To continue the experiment after the coatings had been inserted, the acidic slurry was pumped back into the reactor.

To prepare the erosive particles for experimentation they were initially washed to remove trace chemicals, then pre-leached for $24 \mathrm{~h}$ in a $0.15 \mathrm{M}$ solution of $\mathrm{H}_{2} \mathrm{SO}_{4}$ at ambient temperatures in stirred conditions. 


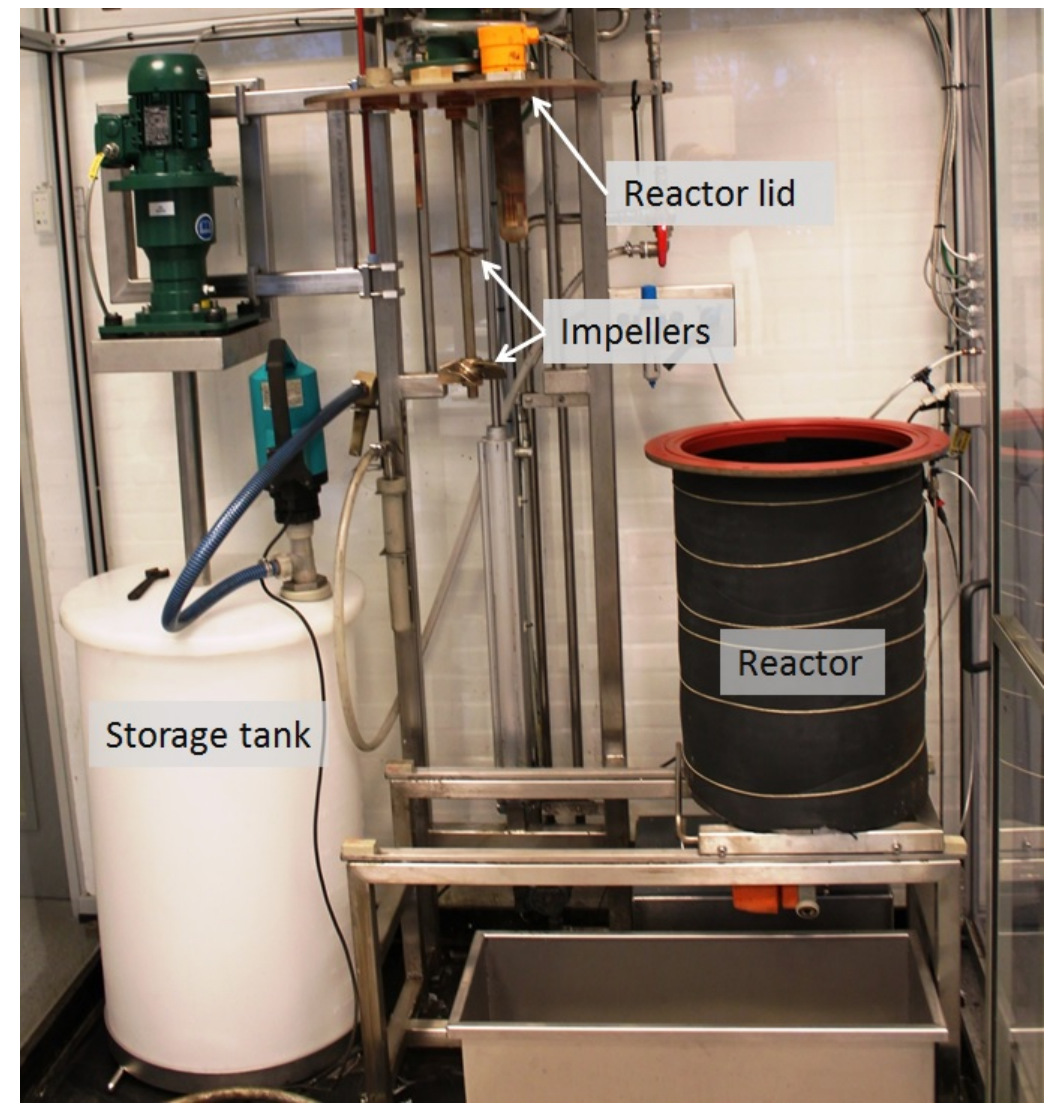

Figure 4: The pilot-scale set-up. The reactor lid has been lifted via a pneumatic crane and the reactor moved to the side, allowing access to the samples inside. A storage tank is available for storing the slurry solution while handling coating samples.

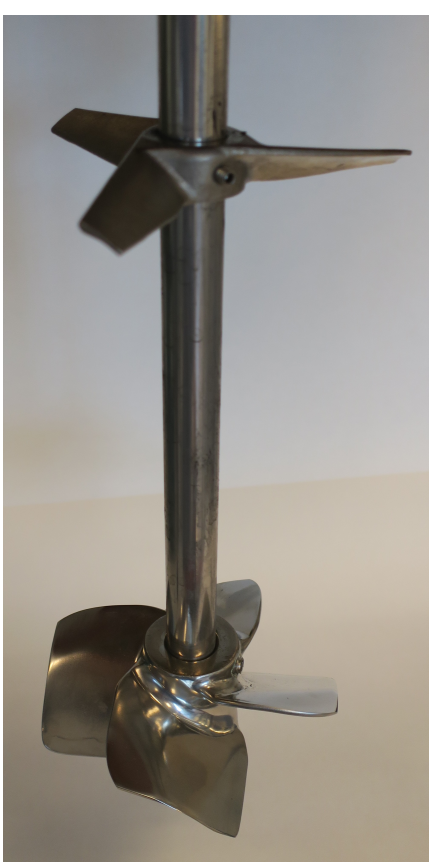

Figure 5: The two impellers used in the tank. The top impeller is a Lightnin A310, the bottom one a Lightnin A315. 


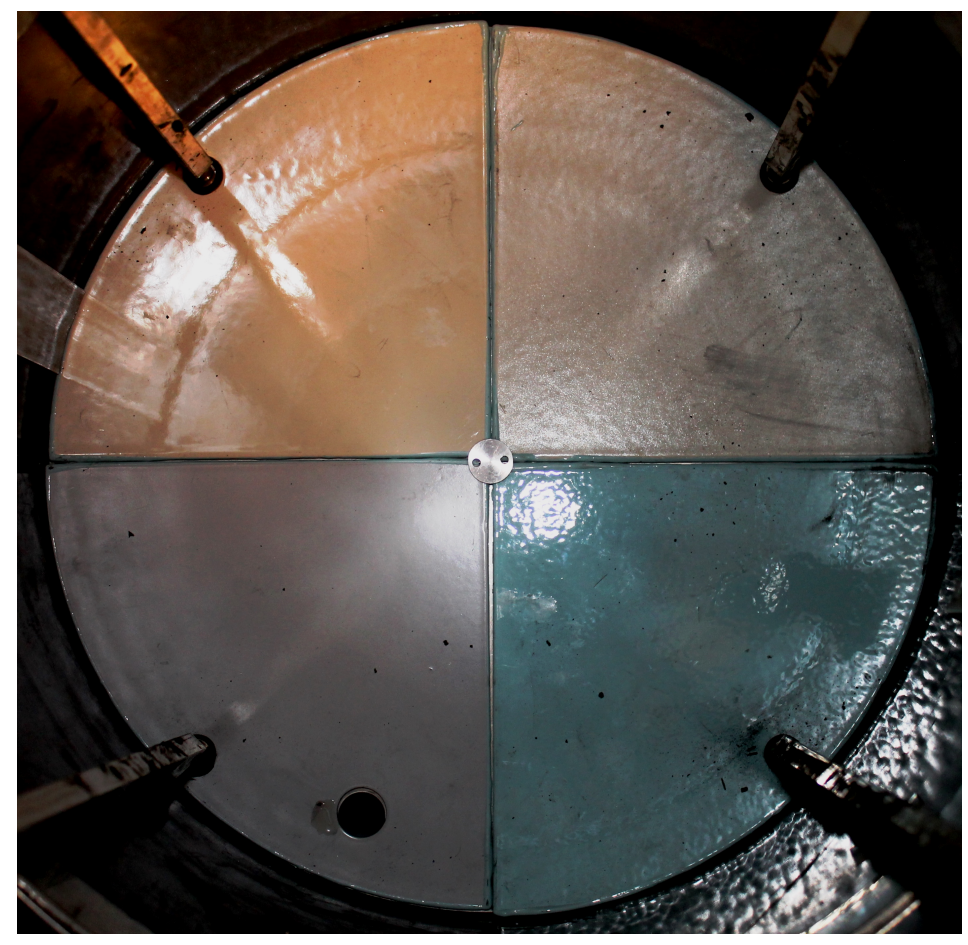

Figure 6: Four different coating samples inside the leaching reactor. Each sample can be removed and re-inserted into the reactor during an experimental series.

Immersion experiments

Coating samples were immersed in jars containing the selected chemical solution and placed in a temperature regulated oven. The samples were periodically removed, every three to four days, dried with paper towels for visual inspection and DFT analysis and thereafter re-immersed.

\section{DFT readings}

All DFT readings were performed using an Elcometer 355 with a non-ferrous probe. The Elcometer was calibrated before use on 316 SS plate using a $525 \mu \mathrm{m}$ standard. Readings on the coating were performed 15 to 30 minutes after sample removal from the chemical environment. Guiding templates, Fig. 7, were used to measure the same points on the coating surface for every consecutive inspection, allowing one to track the DFT change of each individual point at 
known positions. This reduces the measurement uncertainty to $\pm 1.5 \mu \mathrm{m}$ and was particularly important for tracking polishing rates in the reactor experiments.

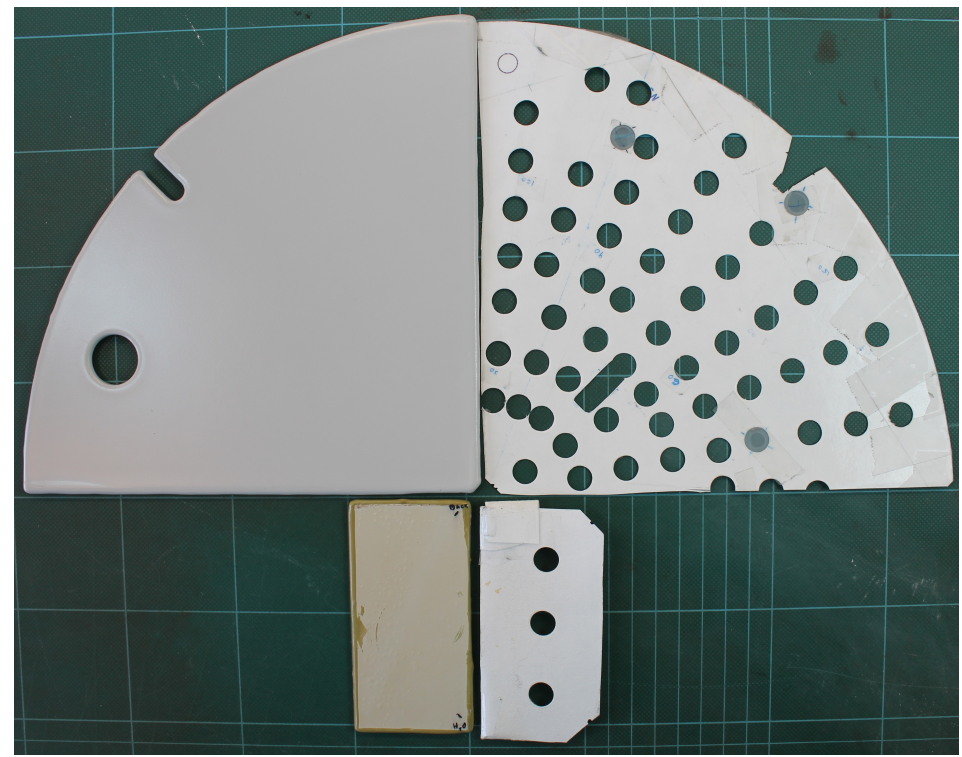

Figure 7: Reactor (top) and immersion (bottom) samples shown to the left. On the right hand side, the measurement guiding templates for DFT measurements are shown. The templates helped to perform readings on the same area on the coating samples, at each point in time.

\section{SEM imaging}

Scanning electron microscopy imaging was performed using an Inspect S. with energy-dispersive X-ray spectroscopy (EDS) to perform elemental analysis.

To prepare coating samples for cross-sectional analysis in the SEM, previously immersed freefilms were shaved using a Microtome Finesse 325. The Microtome uses a sharp blade with precision, to cut and expose the coating cross-section as a smooth planar surface. The sample is adjusted so the blade cuts parallel to the diffusion front minimizing any smearing effects which might distort the determination of penetration depth. To avoid sample charging, the coating samples were coated with a four nm layer gold, by physical vapor deposition using a Quorum 
Coater.

\section{Results and discussion}

This section describes how DFT changed for the coatings in immersion and reactor experiments, and how this data can be used to estimate coating lifetime. Observed phenomena such as radial position-dependent polishing rates, and $\mathrm{pH}$ dependent polishing rates are also discussed and a degradation mechanism is suggested.

Reactor experiments lasted around seven weeks, this time was chosen to ensure a DFT trend would be observed, while keeping the experimental time as short as possible. However, coatings NE2 and NE3 were unable to stay intact long enough to gather useful data. Under both Mild and Harsh conditions, blisters were found on NE2, obscuring erosion effects, while NE3 degraded and delaminated within the first day. The NE1 coating delaminated after around 15 days under Harsh conditions, but DFT data could be obtained until the failure occurred. Fig. 8 shows the NE1 and NE2 failures on immersion samples. The turbulent liquid flow stripped the reactor samples of all coating after failure. 


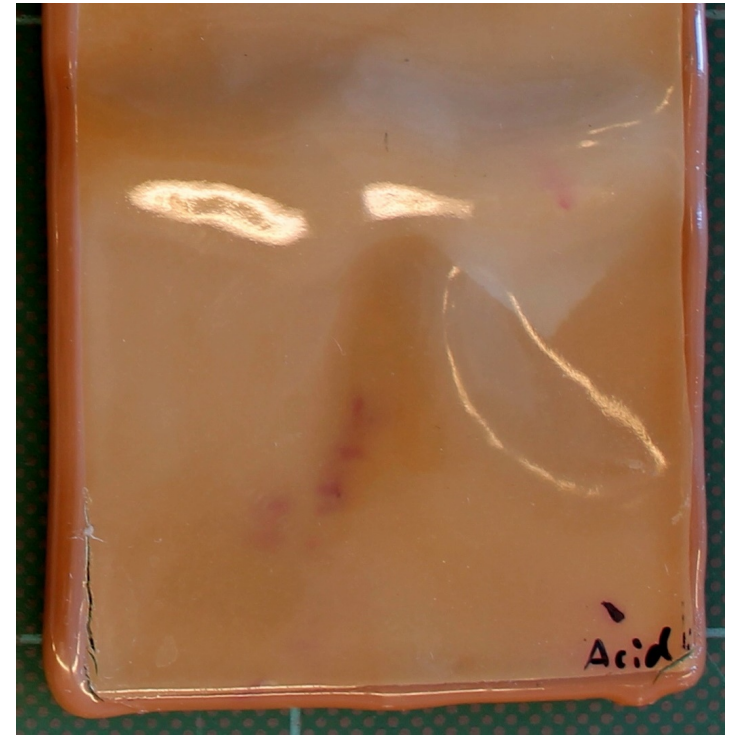

(a) Novolac epoxy, $100 \%$ solids (NE1), 15 days

(b) Novolac epoxy (NE2), 17 hours exposure.

exposure.

Figure 8: Failure of immersion samples in Harsh conditions. Delamination for NE1 and massive blistering for NE2 obscured DFT readings.

\section{Mild condition erosion}

DFT changes during immersion represent the change in thickness caused by chemical immersion alone, while erosive reactor conditions include both chemical and wear effects. The difference between erosive and immersion DFT changes, if any, is a result of coating wear. Potential water erosion was also investigated, and found to be negligible (not shown).

In Fig. 9, DFT changes of the PU, NE1 and VE coatings in immersion and reactor experiments under Mild conditions are shown. Note that each point represents the average thickness change relative to the virgin coating, across the entire sample. Large uncertainties in reactor samples are caused by an inhomogeneous erosion and are discussed in the following section. 


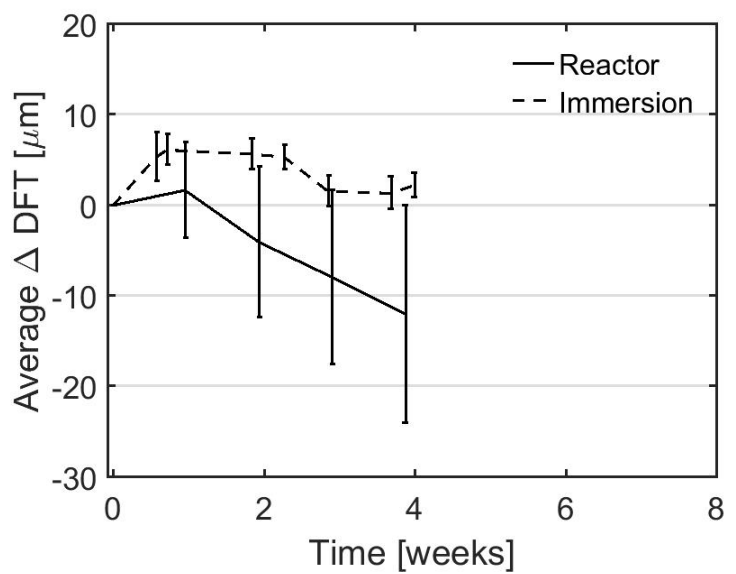

(a) Polyurethane (PU)

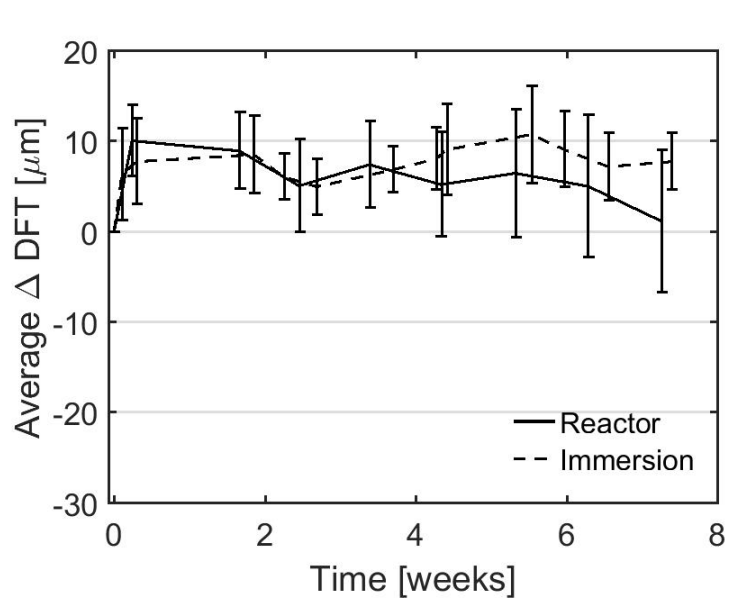

(c) Vinyl ester (VE)

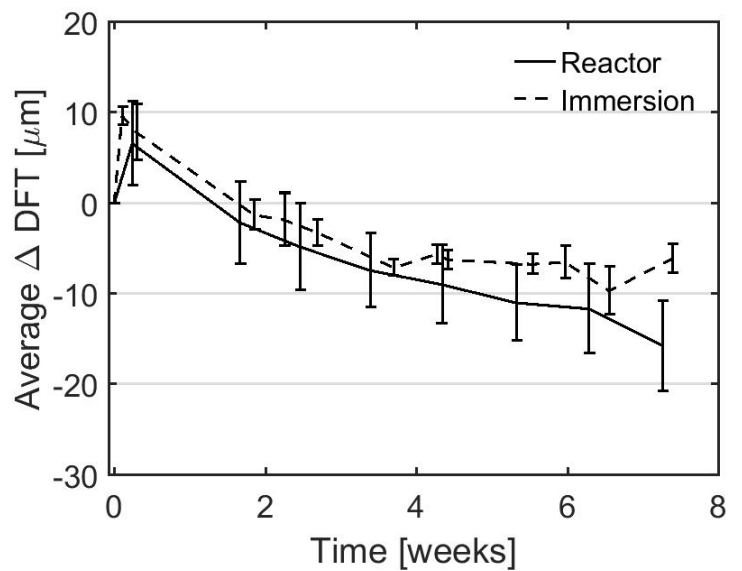

(b) Novolac epoxy (NE1) 
sample stopped swelling and maintained its thickness, while the reactor sample thickness steadily decreased as time passed. In Mild conditions, coating performance in descending order is as follows: $\mathrm{VE}>\mathrm{NE} 1>>\mathrm{PU}$.

\section{Harsh condition erosion}

Fig. 10 shows DFT changes from immersion and reactor experiments in Harsh conditions.

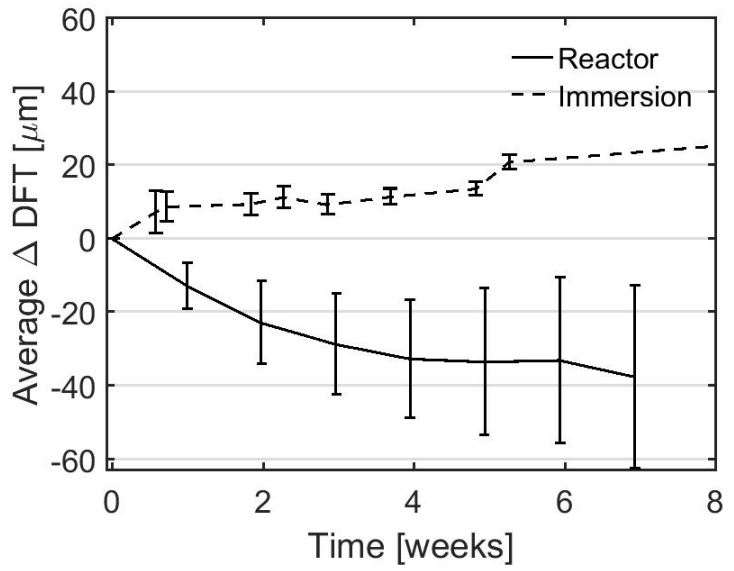

(a) Polyurethane (PU)

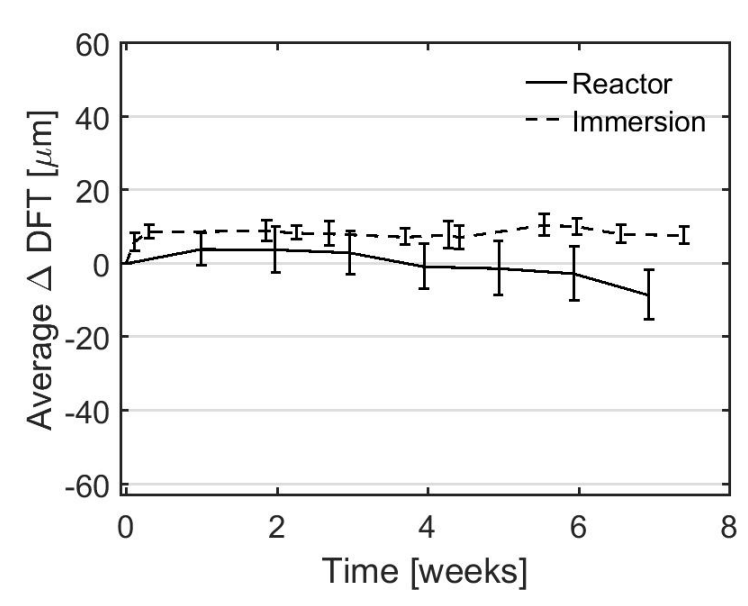

(c) Vinyl ester (VE)

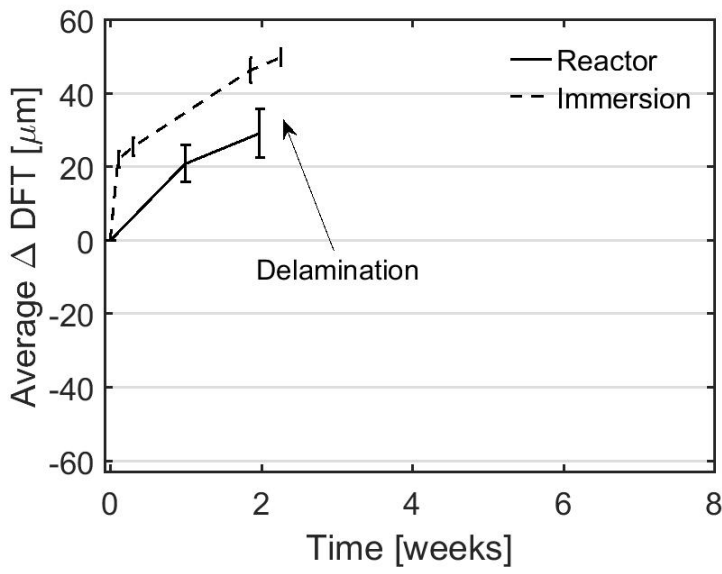

(b) Novolac epoxy (NE1)

Figure 10: DFT changes of coatings during immersion and reactor experiments in Harsh conditions. NE1 delaminated between 400 and $500 \mathrm{~h}$ for both reactor and immersion experiments. 
The PU immersion sample kept gaining thickness, while the reactor sample was worn down by particle impacts. The continued PU swelling in the Harsh conditions affected the perceived polishing rate. Both immersion and reactor NE1 samples delaminated between 14 and 18 days exposure time, after very significant swelling. For the reactor sample, the swelling rate was much greater than the polishing rate as observed by the rise in thickness. Nevertheless, a clear gap was observed between the reactor and immersion sample. The VE immersion sample swelled and maintained its thickness, while the reactor sample swelled only slightly initially, followed by a steady loss in thickness. In Harsh conditions, coating performance in descending order was as follows: $\mathrm{VE}>>\mathrm{PU}>>\mathrm{NE} 1$. The performance of NE1 dropped radically in Harsh conditions because it was unable to handle the low $\mathrm{pH}$ conditions more than $500 \mathrm{~h}$.

Immersed samples have a tendency to rapidly swell and maintain their thickness, but in some cases, like NE1 in Mild conditions, the coating contracted instead, or, like PU in Harsh conditions, the swelling continued. Coating thickness change in the reactor experiments, become a function of their swelling and contracting behavior and magnitude, combined with particle erosion behavior and magnitude. It is therefore necessary to map the thickness change behavior of coating products in immersed conditions, to properly evaluate the rate of polishing caused by erosion.

\section{Varying polishing rates}

Erosive particle impact angle and speed vary with radial distance from a center-placed impeller in a stirred tank [15, 16]. It was therefore investigated whether this had a significant effect on coating polishing rates. Fig. 11 shows the polishing rate of the coating samples for Mild and Harsh conditions. $x$ is the radial position on the coating sample, defined as distance from reactor center divided by reactor radius. With $x=0$ being right beneath the impeller and $x=1$ 
representing the edge of the reactor. Values in Fig. 11 are calculated as the difference between immersion and reactor DFT at a given time. As an example, a wear rate of $0 \mu \mathrm{m} /$ week means zero difference between immersion and erosion experiments and thus no significant erosion. It should be noted that localized blistering for PU in Mild conditions caused DFT values to spike in four specific points, these values have been omitted from Fig. 11a because they do not represent the actual polishing rates.

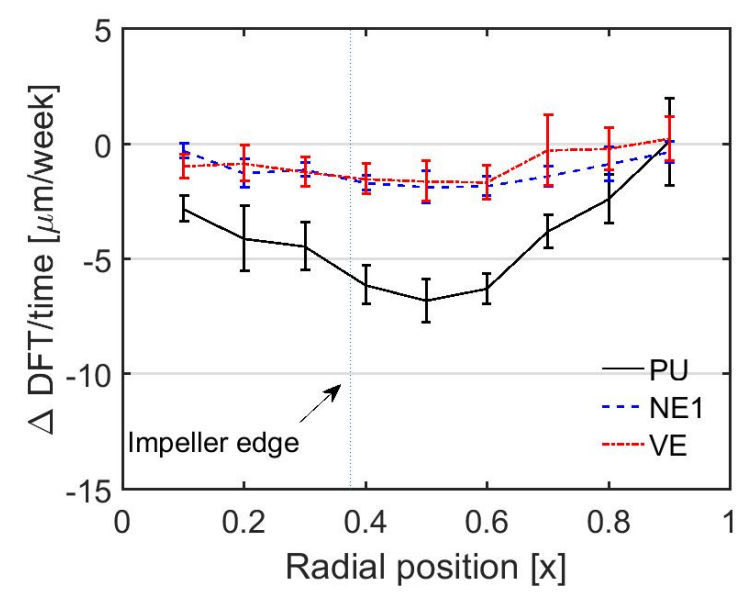

(a) Mild conditions.

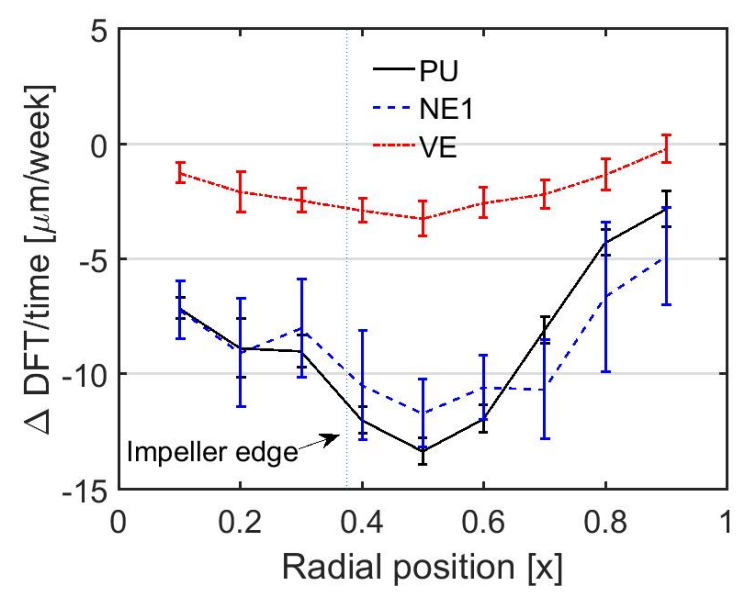

(b) Harsh conditions.

Figure 11: Polishing rates of all coating types in Mild and Harsh conditions as a function of radial distance from reactor center $(x=0)$. Polishing rates are calculated from differences in data from immersion and reactor experiments at the end of the reactor experiment.

It can be seen that polishing rates vary with radial position for every coating in both environments. This has been highlighted in Fig. 12. Neither the steepest particle impact angle $(0 \leq x \leq 0.4)$, nor the highest flow speed $(0.6 \leq x \leq 0.8)$ caused the greatest amount of coating damage. Instead an intermediate speed and impact angle caused the highest polishing rate, more precisely for $0.4 \leq x \leq 0.6$. The polishing rate was less severe towards the reactor edge, $x=1$, and beneath the impeller $x=0$. In Mild conditions, near zero erosion was observed near 


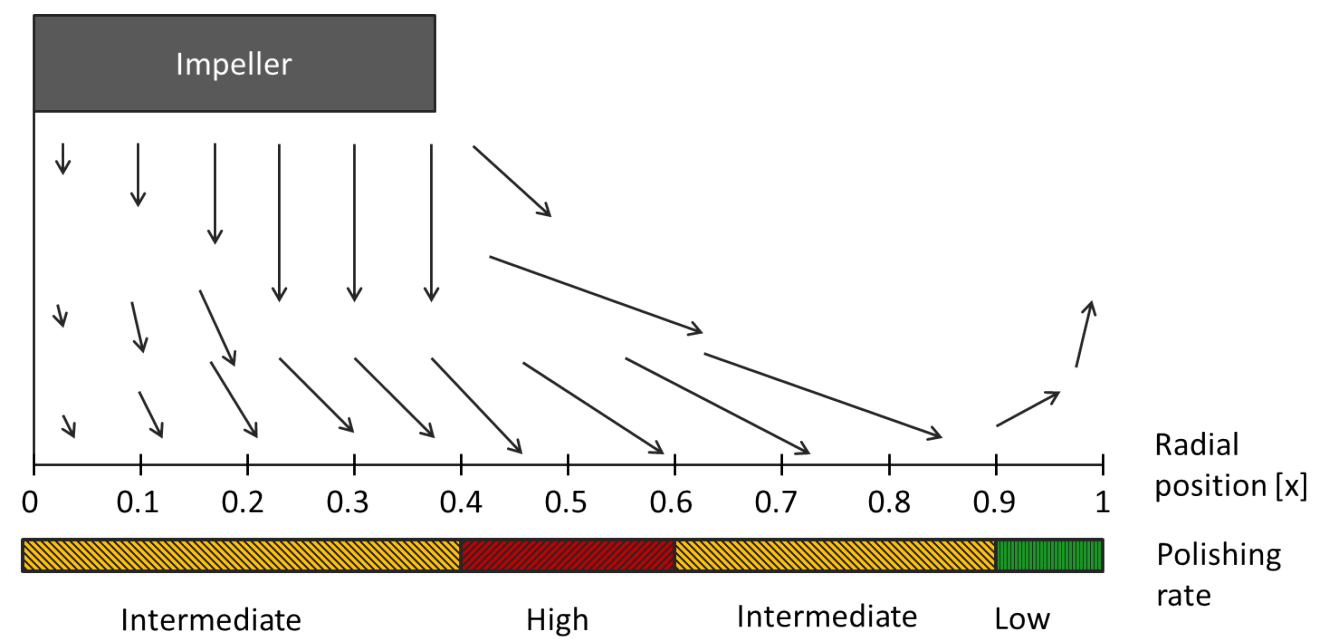

Figure 12: Flow-field vectors on the bottom of the tank as described in reference [16], and the relative polishing rates found in Fig. 11. Position $x=0$ corresponds to the reactor center, and $x=1$ to the reactor wall.

the reactor edge, $x=0.9$, where liquid flow is obstructed by baffles, while in Harsh conditions polishing rates were two to seven times smaller in this region compared to the high erosion area. The area with the highest polishing rate will fail first, and therefore determines the coating lifetime. Based solely on the highest polishing rate, ignoring failure by all other means, a 1000 $\mu \mathrm{m}$ coating would have lifetimes as provided in Table 4. The Vinyl ester resin with glass flakes and titanium oxide fillers, was superior to all other tested coatings in both environments. 
Table 4: The highest observed polishing rate with extrapolated lifetime of a $1000 \mu \mathrm{m}$ coating in both Mild and Harsh conditions. Glass transition temperature and pencil gauge hardness (ASTM D3363) of dry coating samples prior to exposure is also shown.

\begin{tabular}{|c|c|c|c|c|c|c|}
\hline \multirow[b]{2}{*}{ Coating (code) } & \multirow[b]{2}{*}{$\begin{array}{l}\text { Glass transition tem- } \\
\text { perature }\left[{ }^{\circ} \mathrm{C}\right]\end{array}$} & \multirow[b]{2}{*}{$\begin{array}{l}\text { Pencil gouge } \\
\text { hardness }\end{array}$} & \multicolumn{2}{|c|}{ Mild conditions } & \multicolumn{2}{|c|}{ Harsh conditions } \\
\hline & & & $\begin{array}{l}\text { Polishing rate } \\
{[\mu \mathrm{m} / \text { week }]}\end{array}$ & $\begin{array}{l}\text { Estimated } \\
\text { lifetime } \\
\text { [years] }\end{array}$ & $\begin{array}{l}\text { Polishing rate } \\
{[\mu \mathrm{m} / \text { week }]}\end{array}$ & $\begin{array}{l}\text { Estimated } \\
\text { lifetime } \\
\text { [years] }\end{array}$ \\
\hline Vinyl ester (VE) & 145 & $6 \mathrm{H}$ & $1.7 \pm 0.7$ & $11.5 \pm 5.0$ & $3.2 \pm 0.6$ & $5.9 \pm 1.1$ \\
\hline Novolac epoxy $100 \%$ solids (NE1) & 81 & $2 \mathrm{H}$ & $1.9 \pm 0.7$ & $10.2 \pm 3.9$ & $11.7 \pm 1.50$ & $1.6 \pm 0.2$ \\
\hline Polyurethane (PU) & 25 & $\mathrm{H}$ & $6.2 \pm 0.8$ & $3.1 \pm 0.4$ & $13.4 \pm 0.6$ & $1.4 \pm 0.1$ \\
\hline
\end{tabular}


$T_{g}$ and hardness effects

Coating hardness is a key property when it comes to erosion resistance [17], however, for the selected coatings, hardness had little to no effect on the polishing rates. The hardness difference $6 \mathrm{H}$ to $2 \mathrm{H}$, for $\mathrm{VE}$ and $\mathrm{NE} 1$ respectively, did not results in a big difference in the Mild condition polishing rate (see Table 4). The difference from $2 \mathrm{H}$ to $\mathrm{H}$, for $\mathrm{NE} 1$ and $\mathrm{PU}$ respectively, was therefore not the cause of PU's relatively high polishing rate in Mild conditions. The $\mathrm{T}_{\mathrm{g}}$ of PU, on the other hand, can account for this difference. Operating above a coatings $\mathrm{T}_{\mathrm{g}}$ can cause a deterioration of mechanical properties. The high temperature environment will alter the hardness properties because the resin is softened by heating. The $\mathrm{T}_{\mathrm{g}}$ of $\mathrm{PU}$ was $25^{\circ} \mathrm{C}$, and was below the experimental temperature of $75{ }^{\circ} \mathrm{C}$, while the NE1 and VE Tg were above this threshold.

\section{Chemical reaction effects}

It is possible for chemicals to react with the coating resin or fillers, cleaving inter-molecular bonds or dissolving hard fillers, thus altering mechanical properties of the coating surface. This is evident when comparing the polishing rates in Mild and Harsh condition exposure. The added stress of low $\mathrm{pH}$ exposure decreases the erosion resistance of all selected coatings by reacting with the resin and/or fillers. In a recent review [2], certain functional groups in cured coating resins were reported as vulnerable to acidic hydrolysis, which would cause chain scissoring in the resin matrix and thus change surface mechanical properties. These groups include amine linkages in NE1, urethane linkages in PU, and ester bonds in VE. Also fillers like the 9.3 wt.\% calcium carbonate found in PU, can react with sulfuric acid.

The performance of NE1 coating in particular, was worsened in Harsh conditions. Weight change experiments of immersed free films revealed a rapid weight increase, within the first day of 
exposure, see Fig. 13, NE1 looses its barrier properties in Harsh conditions resulting in a fast acid diffusion compared to PU and VE. It is likely that reactions between the coating and sulfuric acid, caused the loss in coating barrier properties. This reaction also increased the polishing rate by a factor of six, despite NE1 having a $\mathrm{T}_{\mathrm{g}}$ above the experimental conditions and a hardness that proved sufficient in Mild conditions.

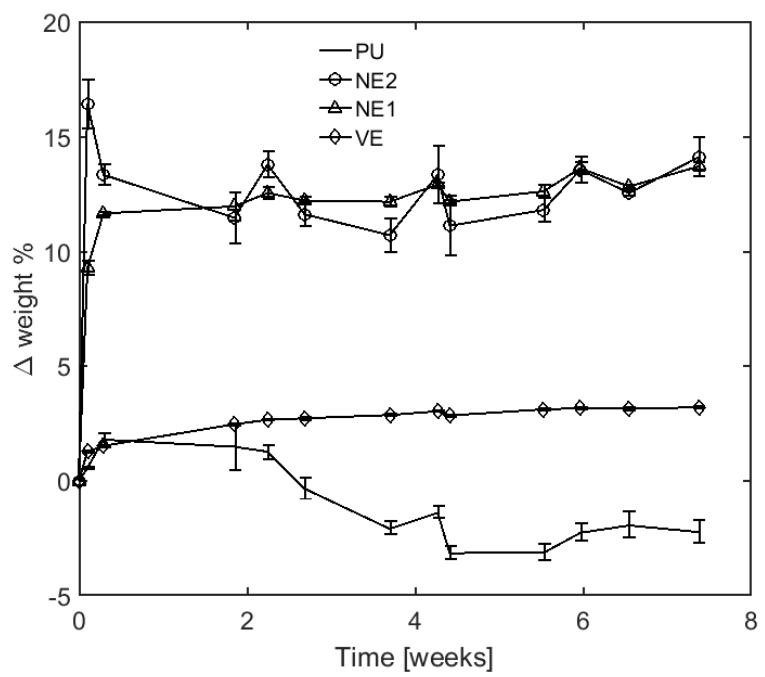

Figure 13: Percentage weight change of free coating films immersed in Harsh conditions.

\section{Polishing and reaction mechanism}

A suggested mechanism for simultaneous polishing, liquid diffusion and reaction is visualized in Fig. 14. Molecules diffuse into the coating surface and change the mechanical properties by softening, swelling and/or reacting with the resin. Erosive particles continuously polish away the mechanically compromised surface, enabling further ionic diffusion. The mechanism bears similarity to erosion/corrosion effects commonly found in metals, where mechanical properties of a surface layer are altered due to chemical reactions with the environment, making it more vulnerable to erosion [5]. 


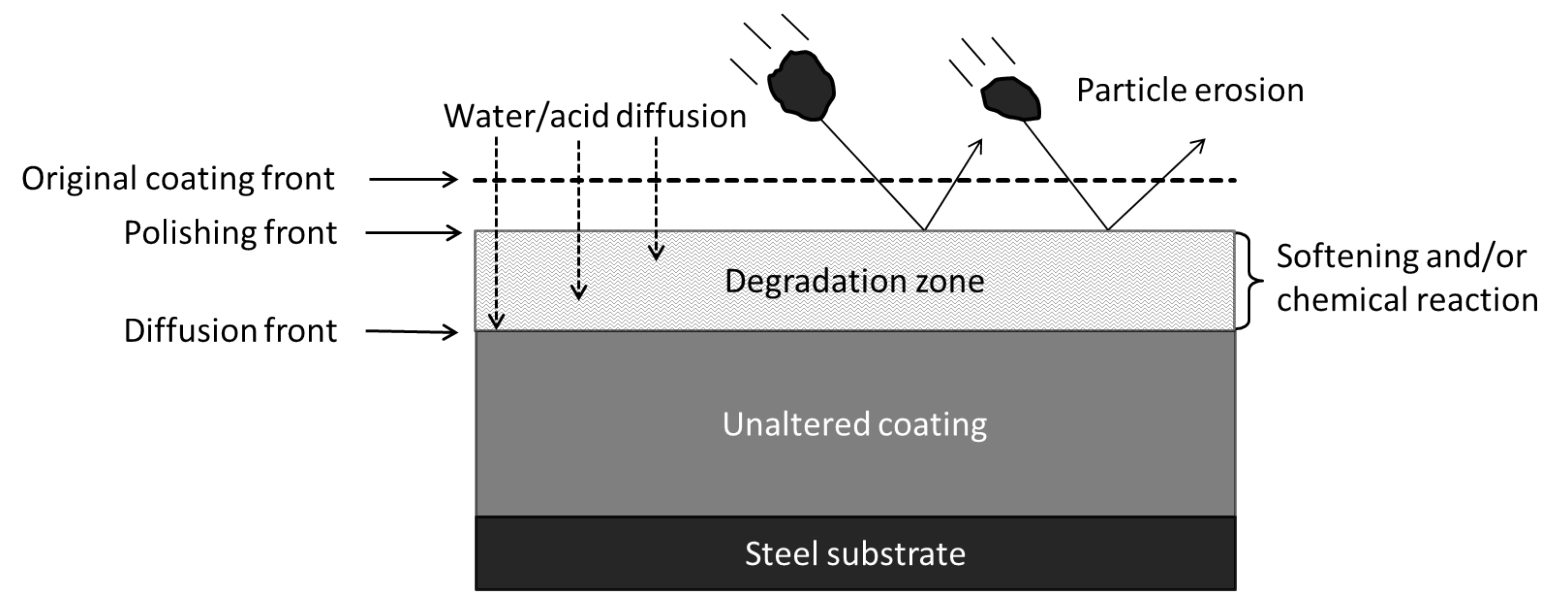

Figure 14: Proposed erosion/corrosion mechanism for organic coatings. Liquid diffuses into the film thereby softening and/or reacting with the coating; this affects the polishing rate.

Liquid diffusion into a coating creates a degradation zone. The thickness of this zone depends on the diffusion front and the polishing front. Methods for determining polishing rates are described in the current paper, while diffusion rates of an acid through a coating can be found using diffusion cells. Diffusion cells were described in [18], where diffusion coefficients for VE, PU and NE1, were also provided.

The mechanical properties of a coating can be altered in the degradation zone. The coating is softened by the penetrant, reducing the coating $T_{g}$. Reactions may also occur in this zone, the severity of which can have a significant influence on the mechanical properties, and thereby the polishing rate. So, the polishing rate is enhanced by acid diffusion, and the acid diffusion can be accelerated by the removal of coating surface layers.

A visual example of the degradation zone is seen in Fig. 15, which shows a cross-sectional image of a free NE2 film immersed in Harsh conditions. The sulfuric acid diffusion front is visible through the sulfur element signal. Furthermore, the diffusion front leaves a visibly damaged degradation zone. Similar images were taken of NE1, NE3, PU and VE, but the barium sulfate (baryte) filler in NE1, NE3 and PU obscured the S-element signal, while the signal in VE was 
too weak to distinguish.

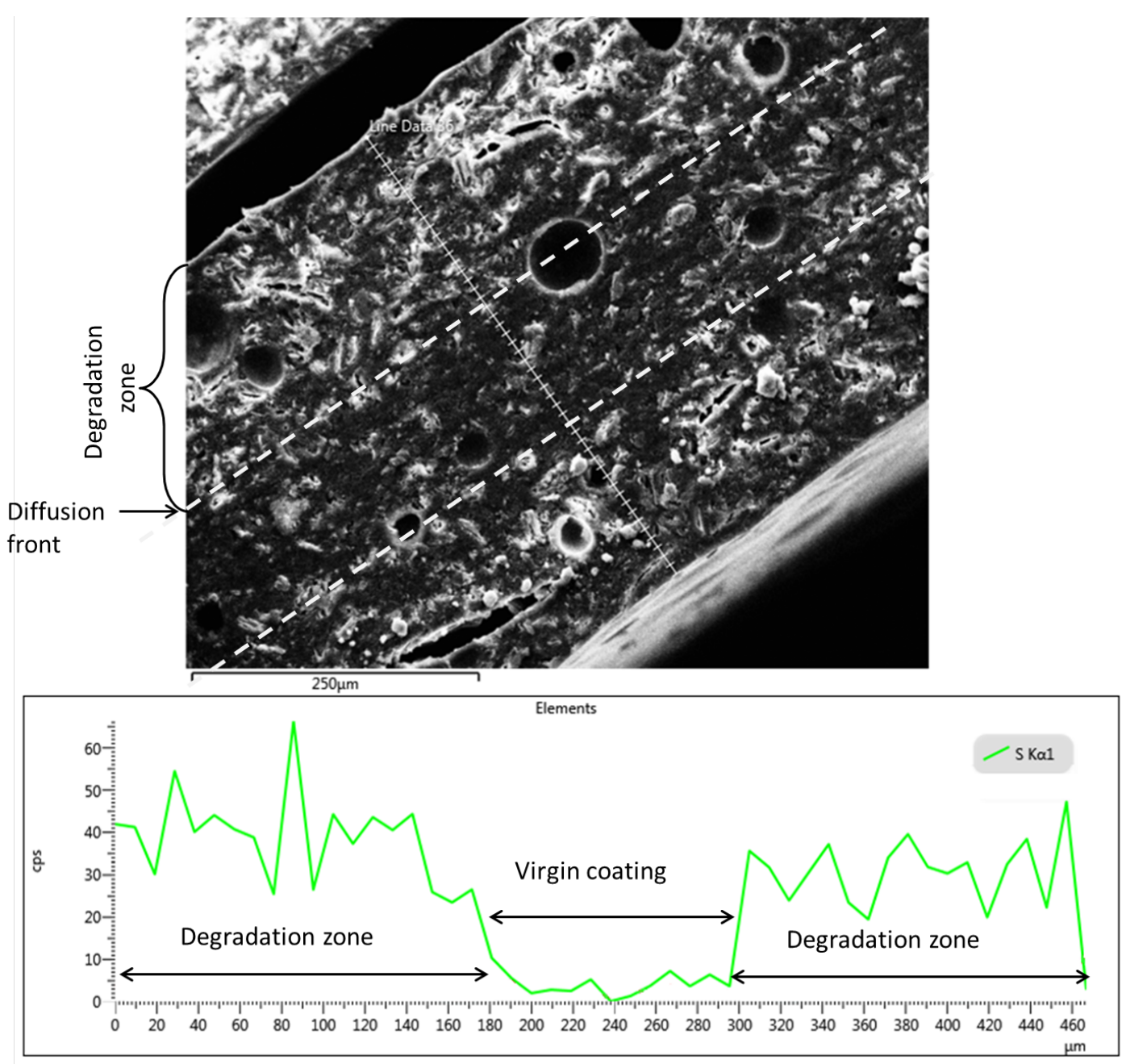

Figure 15: SEM image (top) of a cross section of NE2 free film (i.e. diffusion from both sides), immersed two hours in Harsh conditions. Dotted lines represent the diffusion front. The line-scan (bottom) shows sulfur signal intensity across the film.

\section{Conclusions}

In the current study, coating film thickness change was found to be a function of physical interactions with the environment such as swelling or film contraction, as well as mechanical erosion. The ability to monitor polishing rates on a large amount of individual points on a coating sample, 
led to the discovery of a high variance of these rates, on the reactor samples along the radial position. The highest polishing rates were found below the tip of the axial pumping impeller for all coating types, whereas the lowest polishing rates were found near the reactor wall. Positional dependencies were caused by differences in particle speed and impact angle.

The mechanical properties of coatings determine their erosive resistance, and the immersion environment influences these properties. Increasing the $\mathrm{H}_{2} \mathrm{SO}_{4}$ concentration in a chemical slurry increased the polishing rates of the organic coatings. Polishing rates of the vinyl ester (VE) and polyurethane (PU) coatings were doubled in the harsh acidic slurry compared to the more neutral, mild, slurry. The novolac epoxy (NE1) polishing rates were increased by a factor of six. The cause of this increase can be speculated to be due to chemical reactions between the acid and coating resin and/or fillers, leading to a change in the mechanical properties of the coating surface. This change caused the surface to be more susceptible to erosion from the impacting particles.

For the coatings tested, the vinyl ester (VE) showed best performance in all conditions. Novolac epoxy (NE1) performed well in the neutral slurry, but deteriorated in the acidic slurry. The other epoxies, NE2 and NE3, failed rapidly in both conditions. The polyurethane (PU) showed poor erosion resistance in both environments because conditions were above the glass transition temperature of the coating. The vinyl ester was determined to have a lifetime of approximately six years per $1000 \mu \mathrm{m}$ applied thickness in the acidic slurry conditions representing the agitated leaching environment, making it applicable in industrial operations.

Organic thermoset coatings can be used as protective coatings in agitated leaching tanks. However, to explore the viability of protective coatings, one has to assess factors like erosion resistance in the same environment as the intended use, because chemical exposure, and other environmental factors such as temperature, can have a significant effect on polishing rates. 


\section{Acknowlegdement}

This work is part of the project 'Minerals and Cement Process Technology - MiCeTech' funded by Innovation Fund Denmark, FLSmidth A/S, Hempel A/S, the Hempel Foundation, and the Technical University of Denmark (DTU).

\section{References}

[1] Kelley, D, "How to reduce construction and maintenance costs in metal extraction and refining processes", in: SME Annual Meeting and Exhibit, pp. 326-329 (2010)

[2] Møller, VB, Dam-Johansen, K, Frankær, SM, Kill, S, "Acid resistant organic coatings for the chemical industry: a review", Journal of Coatings Technology and Research 14 279-306 $(2017)$

[3] Duby, P, "Metallurgy", in: Kirk-Othmer Encyclopedia of Chemical Technology, John Wiley and Sons (2005)

[4] Lossin, A, "Copper", in: Ullmann's Encyclopedia of Industrial Chemistry, pp. 467-497, Wiley-VCH (2001)

[5] Møller, P, Nielsen, LP, Advanced surface technology: volume 1, Moeller and Nielsen (2013)

[6] Clark, HM, Burmeister, L, "The influence of the squeeze film on particle impact velocities in erosion", Int. J. Impact Eng. 12 415-426 (1992)

[7] Hojo, H, Tsuda, K, Yabu, T, "Erosion damage of polymeric material by slurry", Wear 112 $17-28(1986)$ 
[8] Barkoula, NM, Karger-Kocsis, J, "Processes and influencing parameters of the solid particle erosion of polymers and their composites", J. Mater. Sci. 37 3807-3820 (2002)

[9] Bai, H, Stephenson, A, Jimenez, J, Jewell, D, Gillis, P, "Modeling flow and residence time distribution in an industrial-scale reactor with a plunging jet inlet and optional agitation", Chem. Eng. Res. and Design 86 1462-76 (2008)

[10] Chaiko, D, Baczek, FA, Rocks, SS, Walters, T, Klepper, R, "The FLS rapid oxidative leach (ROL) process. Part I: mechano-chemical process for treating chalcopyrite", in: Com 2015, August (2015)

[11] Nienow, AW, "The suspension of solid particles", in: Mixing in the Process Industries, pp. 364-393, Reed Educational and Professional Publishing Ltd (1997)

[12] Clement, KH, Fangel, P, Jensen, AD, Thomsen, K, Kemiske enhedsoperationer, Polyteknisk Forlag, Copenhagen, Demnark, 5 edn. (2004)

[13] Eyzaguirre, C, Rocks, SS, Klepper, R, Baczek, FA, Chaiko, D, "The FLSmidth rapid oxidative leach (ROL) process: a mechano-chemical approach for rapid metal sulfide dissolution", in: Hydroprocess, vol. 7th, pp. 1-11 (2015)

[14] Staff., J, "Coating systems for concrete in severe service: A brief discussion", J. Prot. Coat. Linings 23 50-57 (2006)

[15] Ayranci, I, Machado, MB, Madej, AM, Derksen, JJ, Nobes, DS, Kresta, SM, "Effect of geometry on the mechanisms for off-bottom solids suspension in a stirred tank", Chem. Eng. Sci. 79 163-176 (2012)

[16] Ge, CY, Wang, JJ, Gu, XP, Feng, LF, "CFD simulation and PIV measurement of the flow 
field generated by modified pitched blade turbine impellers", Chemical Engineering Research and Design 92 1027-1036 (2014)

[17] Oka, YI, Yoshida, T, "Practical estimation of erosion damage caused by solid particle impact: Part 2: Mechanical properties of materials directly associated with erosion damage", Wear 259 102-109 (2005)

[18] Møller, VB, Wang, T, Dam-Johansen, K, Frankær, SM, Kill, S, "Determining acid barrier properties of organic coatings using a diffusion cell array", Submitted December 2017 to Journal of Coatings Technology and Research 